Revista de la red interuniversitaria de estudios sobre las literaturas rioplatenses contemporáneas en Francia

$18 \mid 2018$

El río y la ciudad

\title{
Isleña
}

\section{Cristina Iglesia}

\section{OpenEdition}

Journals

\section{Edición electrónica}

URL: http://journals.openedition.org/lirico/5723

DOI: $10.4000 /$ lirico.5723

ISSN: 2262-8339

Editor

Réseau interuniversitaire d'étude des littératures contemporaines du Río de la Plata

\section{Referencia electrónica}

Cristina Iglesia, «Isleña », Cuadernos LIRICO [En línea], 18 | 2018, Puesto en línea el 14 octubre 2018 consultado el 21 abril 2019. URL : http://journals.openedition.org/lirico/5723 ; DOI : 10.4000/ lirico. 5723

Este documento fue generado automáticamente el 21 abril 2019.

\section{(c) $(1) \Theta \Theta$}

Cuadernos LIRICO está distribuido bajo una Licencia Creative Commons Atribución-NoComercialSinDerivar 4.0 Internacional. 


\section{Isleña}

\section{Cristina Iglesia}

No tuve amigos ni amigas de verdad hasta el segundo año de la secundaria. En ese momento, milagrosamente, el aislamiento en el que había vivido hasta entonces y que preocupaba a toda mi familia se convirtió, sin previo aviso, en una explosión de posibilidades conjuntas de riesgos, de secretos, de aventuras, de miedos, de risas y de lágrimas con destinatarios de rostros y nombres propios.

Pero antes, mucho antes de esta actividad frenética de la adolescencia en Corrientes y justamente durante el tiempo en que fui huraña y solitaria tuve, sin embargo, mi pequeño y silencioso círculo virtuoso en el trío que formaba con Pelo y Lati cada vez que llegábamos con mis padres y mis hermanos a la isla del Cerrito y que se disolvía, literalmente, cuando regresábamos a la ciudad. Desde la cuna (una cuna de mimbre que se transportaba fácilmente) hasta el comienzo de la escuela secundaria viajé cada semana con mis padres a la Isla del Cerrito, un lugar paradisíaco y misterioso ubicado en la confluencia de dos ríos. La isla tenía algunos pocos pobladores "nativos" pero, en gran parte de su territorio, albergaba las instalaciones del Hospital Maximiliano Aberastury, que funcionaba en un moderno complejo de edificios. Sin duda, la idea de un mundo retirado, autoabastecido, subyacía a esta reproducción sobre el agua de un falansterio fourierista intervenido por la medicina, destinado a aislar, a tratar y, si la esperanza 
científica lo permitía, a curar a los pacientes atacados por el mal de Hansen, a los enfermos de lepra.

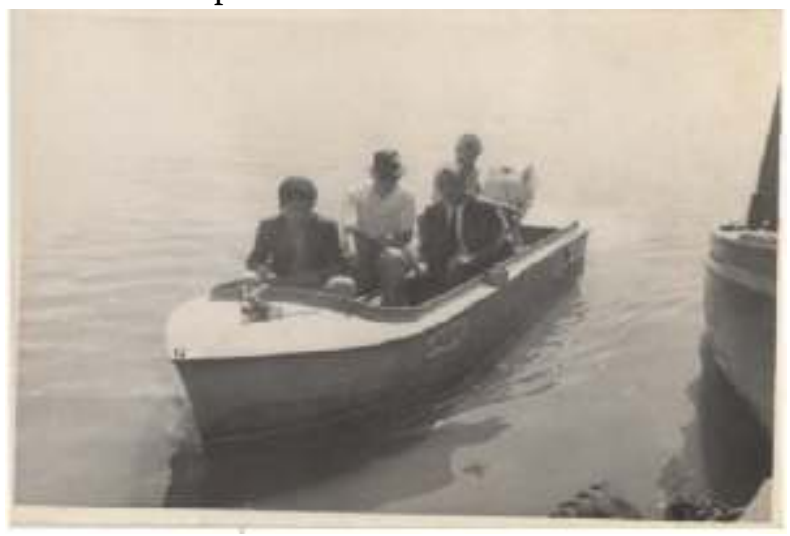

Figura 11

Mi padre fue médico interno y luego director del hospital durante décadas, y su vida y la de su familia -que iría creciendo en esos años- serían marcadas para siempre por la experiencia del viaje sobre el río que se repetía cada semana con calor o con frío, con buen tiempo o con lluvia. Partíamos desde la ciudad de Corrientes en la picap que nos permitía viajar atrás a cielo abierto durante casi dos horas por un camino de tierra en mal estado que nos dejaba en Paso de la Patria; desde allí en bote o en lancha descubierta cruzábamos el río hacia la isla que nos esperaba enfrente y que encerraba tanta belleza y tanto dolor. Ahí, en ese micromundo que nos convertía en otros ni bien trepábamos por la escalinata de tierra, la medicina enfrentaba un desafío extremo: encontrar el tratamiento adecuado y la posible cura para una enfermedad milenaria signada por el estigma del pecado y el castigo de la deformidad.

El leprosario albergaba a la comunidad de médicos, enfermeros, policías, carteros, panaderos, cocineros, mozos, albañiles, jardineros, quinteros y personal de limpieza que constituía la dotación de población "sana" de la isla y, por supuesto, a los pacientes que ocupaban las salas de camas de hierro blanco -los internados- y los que vivían, solos o en parejas, en ranchos modestos rodeados de una pequeña huerta cuya producción servía para abastecer parcialmente su propio sustento. La parte "sana" se diferenciaba bruscamente de la parte "enferma" con una línea de pintura roja en tablones de madera atados a un alambrado que anunciaba la prohibición de pasar a lo que en la jerga de la isla se llamaba "la zona", pero en ambos lados de la línea roja la exuberancia del monte -que no se dejaba dominar por marcas humanas- convertía el todo en un murmullo verde de hojas, de pájaros, de monos, de chicharras que acompasaba, junto con el rumor del río y del viento, la vida entera del Cerrito.

Tengo dos comorecuerdos de ese entonces: el primero está formado por múltiples sonidos y tiene que ver con ese murmullo permanente, que apenas cambiaba de intensidad por las noches, que sólo desaparecía cuando nos alejábamos por el río y que era lo primero que me hacía sentir que estábamos llegando y que me acompañaba en las siestas interminables; el segundo está formado por un sentimiento: la enorme culpa por ser sana, por entrar y salir libremente de un lugar en el que la mayoría de sus habitantes no podía hacerlo. Lo único que la mitigaba, en cierto modo, era la sensación de pertenecer al bando de las fuerzas del bien, ser la hija del hombre que podía ayudarlos a combatir la enfermedad o, en cualquier caso, a vivir mejor. Mi padre, alto y delgado, vestido siempre con su delantal blanco, era el héroe indiscutible de esta historia y desde que pude entender su lugar central en el sistema social de la isla comencé a rogarle que me dejara 
acompañarlo en sus recorridos, que me dejara, en fin, atravesar la temible línea roja, cruzar el alambrado que separaba el bajo de la zona. "Vamos a ver", decía mi padre, y eso era todo lo que escucharía al respecto hasta el próximo momento en que me animaría a volver a pedírselo. Entre tanto, mientras iniciaba sin saberlo el duro aprendizaje de esperar algo deseado y también temido, me juntaba en la galería espaciosa con Pelo y Lati, dos chicos cuyas familias vivían en la isla desde siempre.

Pelo llegaba por el lado del sendero de la playita, y se lanzaba sobre mis revistas de historietas. Lati parecía salir del interior del monte que crecía hasta enfrente de la casa y de inmediato me pedía que trajera a Chan. Chan era el mago que contesta, que no era mi juego preferido pero que cargaba invariablemente porque sabía que en el Cerrito tendría con quien jugarlo mientras que en Corrientes ni siquiera me molestaba en abrir la caja que contenía el muñequito de aspecto dudoso (medio buda y medio nada) de cerámica oscura que sostenía entre sus manos una varita mágica que se apoyaba siempre en el lugar de la respuesta justa.

Mientras jugábamos a encontrar esa respuesta (qué bandera correspondía a qué país o qué nombre a la capital de cada cual) hablábamos, como al pasar, de lo que realmente importaba: compartíamos cuentos cuyos protagonistas casi siempre eran enfermos y pocas, muy pocas veces, personas sanas. La isla era enorme (más de 12.000 hectáreas), pero los tres vivíamos en el pequeño mundo de los sanos. Del mundo de los enfermos, de los irrecuperables, sólo conocíamos fragmentos que nos llegaban en los relatos de los mayores: los enormes pabellones donde vivían, el comedor donde almorzaban y cenaban y las galerías y patios por los que deambulaban. De allí, de la región más oscura y tenebrosa de la isla salían las historias que nos contábamos. Surgían de pronto, como quien no quiere la cosa: uno de los chicos decía "angá el gente de los brazos pelados parece que se convirtió en zorro" o "allá ité parece que hubo fiesta de monstruos la otra noche" y lograba inmovilizarnos, disponernos para la escucha. Yo también aportaba lo mío, pero en mi caso las anécdotas tenían más que ver con bandidos o asesinos que recalaban en la isla, casi siempre heridos y huyendo de la justicia (calculaban y calculaban bien que nadie los iría a buscar entre leprosos), y a los que mi padre decidía curar con la condición de que pasaran a formar parte de una suerte de equipo para todo servicio que funcionaba como guardia de urgencia las veinticuatro horas.

Los chicos hablaban de sucesos y personajes que parecían remotos aunque sucedieran en el otro extremo de la isla; yo hablaba de personas conocidas que formaban parte de la rutina de la administración y de la casa del director (pacíficos albañiles, inofensivos carpinteros, porteros de confianza) pero cuyas historias tenían siempre, en el origen, alguna desgracia, alguna muerte. Nuestro trío se había vuelto conocido por casi todos los que trabajaban en el bajo. A veces nos permitían subir al trencito de carga que recorría el hospital y en la parada de la panadería nos convidaban galletas recién salidas del horno y cuando con su lenta marcha el trencito se adentraba en la zona veíamos, muy de pasada, algunos rostros o cuerpos que se agitaban en saludos y que nosotros hubiéramos preferido no haber mirado nunca.

Yo disfrutaba tanto de las siestas y tardes en la isla, vestida con delantales de colores oscuros hechos especialmente por mi abuela para que me embarrara tranquila, que mi madre ante cada una de mis pequeñas rebeldías cotidianas utilizaba siempre la misma amenaza: "vos no vas más al Cerrito si seguís así". Estaba ligada a esa casa, a esos sonidos, a esos misterios, a esos encuentros con los chicos de un modo especial: allí no necesitaba demostrar que era normal porque nada de lo que me rodeaba en realidad lo era. Allí podía prescindir de las botas ortopédicas, saltearme las meriendas, abandonar los ejercicios 
para corregir los ojos desviados, olvidarme de la pesadilla de las clases de declamación y probar a usar más y más palabras de esa otra lengua que yo no sabía que se llamaba guaraní. Cuando volvía a la ciudad siempre estaba triste y mi único consuelo era saber que nuestro viaje de ida y vuelta al leprosario despertaba el horror pero también la envidia de los chicos del barrio que jamás de los jamases vivirían esa aventura. No podía imaginar entonces que algún día dejaría de sentir ese entusiasmo, que ya no me interesaría ese viaje y que mis hermanos (diez años más chicos) se convertirían en protagonistas del mundo del Cerrito. Casi hacia el final de mi propio ciclo hice, de la mano de mi padre, una visita a uno de los pabellones de mujeres y me quedé un rato conversando con Ramona, una chica muy joven que tenía en su cama una muñeca pelada. Yo había llevado caramelos para convidar, pero no me animé a repartirlos: abandoné la bolsita detrás de una puerta; los caramelos subrayaban mi vergüenza de ser sana y los dejé caer como para alivianarme de esa carga.

No sé exactamente cuándo dejé de ir, pero sí sé que me costó mucho volver a visitar la Isla del Cerrito convertido ahora en un lugar turístico, sin enfermos de lepra ni el micromundo del sanatorio insuflándole un ritmo de vida singular. Regresé después de muchos años invitada por Marcel Czombos, un documentalista excelente, que filmaba los lugares y personajes que Rodolfo Walsh había narrado en sus crónicas del nordeste. La casa del director, que había sido la nuestra, estaba intacta (la recorrí sin vacilar, de memoria, como si hubiera vivido allí hasta hacía poco), pero del hospital sólo quedaban vestigios aislados. No hay adjetivo que pueda describir o insinuar lo que sentí en ese encuentro con los lugares de esa parte de mi infancia. No creo que se vuelva a repetir. Me basta con seguir soñando, de vez en cuando, sueños que fingen suceder en islas que quedan en el medio de dos ríos.

\section{NOTAS}

1. Llegando a la isla (mi padre, con sombrero). 